\title{
Social Causes of the slow-down in health improvement
}

\author{
Michael Marmot \\ Institute of Health Equity \\ Department of Epidemiology and Public Health \\ UCL \\ m.marmot@ucl.ac.uk
}

The abiding view of the second half of the twentieth century is that societies improve, health and social care improve and, as a result, health improves. We can argue, and do, as to who holds the pump handle. How much was it modern medicine, how much organised public health, how much improved social and economic conditions. I argue for social conditions (1). Others argue for medicine and public health(2). Whatever the relative contributions, we are used to health improving year on year, in high income, middle income and most, but not all, low income countries.

We can no longer take such improvement for granted. In England and Wales, Hiam and her colleagues first drew attention to the possibility that mortality rates may actually be increasing in older people(3). At the Institute of Health Equity, we have been monitoring health and its social determinants since the publication of my Review of Health Inequalities, Fair Society Healthy Lives(4). Stimulated by the report of Hiam and colleagues, in 2017, we published results for trends in life expectancy. (http://www.instituteofhealthequity.org/resources-reports/marmot-indicators-2017institute-of-health-equity-briefing/marmot-indicators-briefing-2017-updated.pdf) We said, that since about 1950 life expectancy had been rising by 1 year every 3.5 years among men, and 1 year every five years among women. From 2011 to 2015 this rate of increase halved. My message was that this should be treated with the same urgency as a winter bed crisis. (http://blogs.bmj.com.libproxy.ucl.ac.uk/bmj/2017/09/13/michael-marmot-the-ukscurrent-health-problems-should-be-treated-with-urgency/)

In some ways the failure of health to improve is more important than a winter bed crisis. A winter bed crisis can be solved by proper funding and organisation of the health care system. But, as I stated above, if we attribute improvements in health to improvements in economic and social conditions in society, then decrements in health may perhaps tell us that something is not going well in society.

That something, say Hiam, Harrison, McKee and Dorling in this issue of the Journal ( ), may be austerity-driven cuts to health and social care and an increase in poverty among pensioners. Hiam and colleagues acknowledge that the case is not proven but they, as do I, call for an urgent and systematic enquiry.

I want to talk about society and health, but first a question that was raised with our 2017 report was that perhaps, in England and Wales, we had reached peak life expectancy. Surely, journalists suggested, improvements in life expectancy have to stop some time. A simple answer to that question is provided by comparisons with Europe, as seen in the Figures. In the period 2006-2010, improvements in life expectancy were seen right across 
Europe. The UK was in the middle of the range. In the latter period, 2011-2015, the life expectancy increase slowed in almost all the countries listed, but the slowdown was particularly marked in the UK, second lowest for men, and lowest for women. Three observations. First, we have not reached peak life expectancy; other countries continue to increase more than the UK. Second, the slow down across Europe, post 2010, could well be an effect of the global financial crisis and policies of austerity that were put in place following it. Third, without more detailed analysis, one should be cautious. The claims about the health damaging effects of austerity are credible. But then, why does Greece look better than the UK, and why is Germany doing worse than all other countries listed, bar the UK?

A recent paper from Manchester adds to the evidence that health is giving us an insight into the workings of society.(5) The paper looks at the persistence of health disadvantage in the North of England, compared with the south. One striking finding is the fate of young men in the 1980s. There was no North-South difference at ages 25-34 and mortality rose. Suicide was prominent. Arguably, we are seeing the effect of industrial and social policies in the health statistics. The scorched-earth industrial policies of the $1980 \mathrm{~s}$ with de-industrialisation and mass unemployment wreaked havoc with young people's lives.

If social forces can make things worse, can social policies improve health and reduce inequalities? The New Labour government had an explicit policy to reduce health inequalities building on the Acheson Report(6). There has been speculation that the policy was ineffective.(7) Recent evidence suggests otherwise. Buchan and colleagues from Liverpool examined the gap in life expectancy between the most deprived $20 \%$ of local areas in England and the average, between 1983 and 2015(8). Health inequalities - the gap in life expectancy between the poor areas and the average - were increasing up until 2003. When the New Labour Strategy kicked in, allowing for a lag time, the gap narrowed. A different government changed direction and, after 2012, health inequalities again increased. It would seem that social policy might indeed make a difference.

Armed with that insight it is worth turning attention to the USA. Life expectancy has now declined two years in a row. (https://www.theatlantic.com/health/archive/2017/12/lifeexpectancy/548981//). This shocking news comes on the heels of an influential report from Case and Deaton that showed a rise in mortality in white (non-Hispanic) men and women aged 45-54.(9) The principle modes of death underlying this rise were: poisonings from drugs and alcohol; suicides, and chronic liver disease - what Case and Deaton labelled diseases of despair. I might have called it an epidemic of disempowerment.

A recent analysis looked at the geographic distribution of deaths from drugs, alcohol and suicide and found that the greater the economic distress of an area, the higher the mortality rate. In the industrial Midwest, particularly, the higher the rate of these deaths the greater the 2016 vote for Trump, compared with Romney four years earlier. Trump didn't cause these deaths, but these deaths may have caused Trump. More precisely, economic distress led both to death by drugs, alcohol and suicide and a greater likelihood of voting Trump. (10)

In the UK, we do not have the same appalling toll of drug and alcohol deaths, but we do see higher mortality in areas of economic distress. People in those areas were more likely to 
vote Brexit - perhaps prompted by the same dissatisfactions that led to the Trump vote in the US.

The report by Hiam and these other recent papers reinforce my view that if we want to improve health and reduce inequalities we cannot but focus on the social determinants of health.

1. Marmot M. The Health Gap. London: Bloomsbury; 2015.

2. Deaton A. The Great Escape: Health, Wealth, and the Origins of Inequality. Princeton: Princeton University Press; 2013.

3. Hiam L, Dorling, D., Harrison, D., McKee, M.,. What caused the spike in mortality in England and Wales in January 2015? Journal of the Royal Society of Medicine. 2017;110(4):131-7.

4. Marmot M. Fair society, healthy lives : the Marmot review ; strategic review of health inequalities in England post-2010: [S.I.] : The Marmot Review; 2010.

5. Buchan IE, Kontopantelis, E., Sperrin, T., Chandola, T., Doran, T. North-South disparities in English mortality 1965-

2015: longitudinal population study. J Epid Comm Health. 2017;doi:10.1136/jech-2017209195:1-9.

6. Acheson D. Inequalities in Health: Report of an independent inquiry. London: HMSO; 1998.

7. Mackenbach JP. The persistence of health inequalities in modern welfare states: The explanation of a paradox. Social Science \& Medicine. 2012;75(4):761-9.

8. Barr B, Higgerson, J., Whitehead, M. Investigating the impact of the English health inequality strategy: time trend analysis. BMJ. 2017;358:j3310.

9. Case A, Deaton, A. Rising morbidity and mortality in midlife among white nonHispanic Americans in the 21st century. Proceedings of the National Academy of Sciences of the United States of America. 2015;112(49):15078-83.

10. Monnat SM. Deaths of Despair and Support for Trump in the 2016 Presidential Election. Pennsylvania USA: PennState; 2017. 
Figure: Trends in life expectancy at birth in 25 EU Member States, 2006 to 2010 and 2011 to 2015
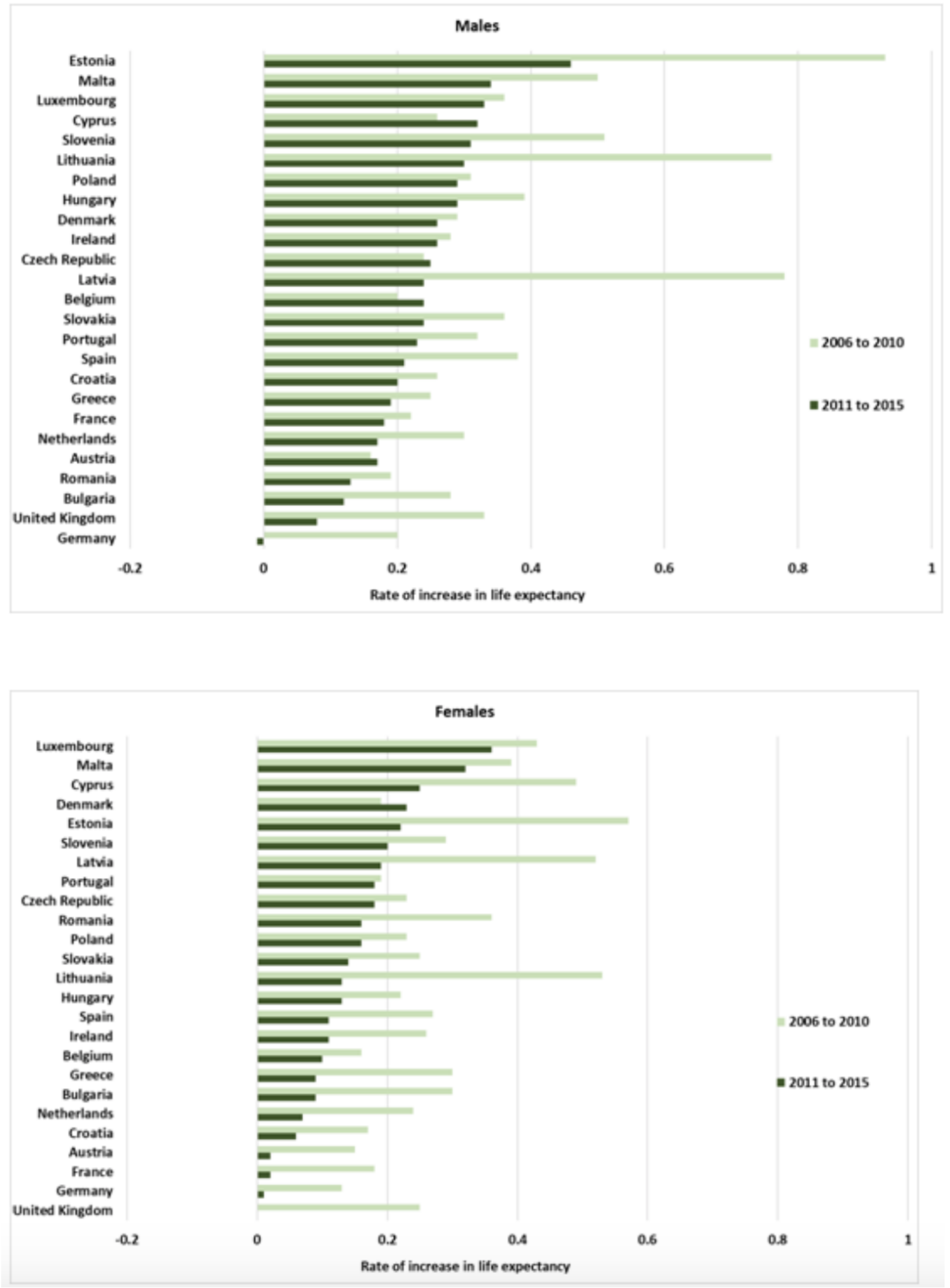